\title{
Los diccionarios como herramientas para el análisis del discurso
}

\author{
Dictionaries as Tools for Analysis of the Speech
}

\author{
Susana Trinidad Ruiz Diaz \\ Universidad Nacional de Asunción, Paraguay \\ Facultad de Filosofía \\ e-mail: sutrinity@gmail.com \\ Recibido: 30/11/2020 \\ Aprobado: 2/03/2021
}

\begin{abstract}
RESUMEN
Este artículo presenta el uso del diccionario como un medio de consulta para comprender el discurso porque bien sabemos que las personas necesitan comunicarse constantemente, pero muchas veces no logran cerrar el proceso comunicativo debido a que el mensaje no fue comprendido. Este hecho puede deberse a diferentes factores, uno de los cuales es la falta de interpretación del discurso, ya sea en forma oral o escrita. En este punto destacamos el valor que tienen los diccionarios como herramientas de consulta ya que a través de ellos se puede lograr entender el significado contextual de las palabras, así como conocer expresiones que pueden tener significados parecidos o contrarios. La metodología utilizada es cualitativa.
\end{abstract}

Palabras claves: Diccionarios, análisis del discurso, significados contextual, sinónimos, antónimos.

\begin{abstract}
This article presents the use of the dictionary as a means of consultation to understand the speech because we well know as it is well-known people that people need to communicate constantly, but many times they cannot conclude the communication process because the message was not understood. This can be due to different factors, amongst which is? the lack of interpretation of the speech, either orally or in writing. At this point we highlight the value of dictionaries as a consultation tool because through them it is possible to understand the contextual meaning of words, as well as to know other expressions that may have similar or opposite meanings. The methodology that has been used is qualitative.
\end{abstract}

Keywords: Dictionaries, discourse analysis, contextual meanings, synonyms, antonyms.

Si nos detuviéramos a reflexionar sobre cada una de las dudas lingüísticas que tenemos podemos darnos cuenta de que no podemos conocer todos los significados de las palabras. Cada día al escuchar la radio, ver la televisión, leer una noticia del periódico, o leer un libro nos encontramos con dos o tres palabras cuyos significados desconocemos, y ¿Qué hacemos para salir de la duda? ¿Dónde recurrimos? Tal vez podamos identificarnos con las respuestas de algunos alumnos: «Lo dejo así»; «pregunto a una persona que sabe más y, si estoy en clases, al profesor». Muy pocos responden que recurren al diccionario. Al plantear la pregunta ¿Por qué no recurren al mismo? Las respuestas son: «No tengo"; "tengo, pero está guardado"; "es muy pesado, si lo traigo a clases capaz me rompa la espalda"; "es muy caro, además para qué lo compraría si solo voy a usarlo este año». Esta última respuesta nos lleva a pensar que, tal vez el uso de esta fuente no es incentivado como material de consulta. Todos, especialmente los docentes, debemos ser conscientes de la importancia de tener un enriquecimiento léxico para poder comunicarnos mejor tanto en forma oral o escrita. "El uso del diccionario puede suponer para el alumno el descubrimiento de las estrategias adecuadas no solo para resolver 
las dudas que se les presentan, sino, sobre todo, para adquirir conciencia de la necesidad de un uso responsable de la lengua» ${ }^{1}$

Es muy frecuente escuchar decir a los profesores de diferentes áreas que sus alumnos se aplazan porque no tienen la capacidad para comprender un texto, o interpretar el planteamiento de un problema y la culpa recae en los docentes de Lengua Castellana porque son ellos quienes debían enseñar bien. Por supuesto que el profesor como actante tiene un impacto en el aprendizaje de los idiomas; sin embargo, creemos que la responsabilidad de orientar a los alumnos hacia un aprendizaje significativo es responsabilidad de toda la comunidad educativa porque la lengua no es privativa de ninguna asignatura. Cada asignatura trata sobre temas específicos del área que están cargados de términos muy propios o, en algunos casos, poseen vocabulario técnico que no son comunes al caudal léxico de los alumnos. Muchas veces, como dicen ellos «logran zafar» porque, si no entienden, lo memorizan y lo repiten sin tener ni la más mínima noción de lo que significa el término/la palabra/el vocablo. En ocasiones, los profesores de otras áreas no toman conciencia sobre la importancia de poseer competencias comunicativas, esto nos hace recordar lo que en algún momento habían planteado algunos docentes «Los profesores de otras áreas no necesitamos conocer cómo se analiza un texto ni que es un sinónimo porque no vamos a ir a plantear esas cuestiones». Debemos saber que todas las personas tenemos la facultad de manifestar nuestras ideas de forma eficaz mediante la competencia comunicativa que nos abre unas de posibilidades para producir o comprender un mensaje. "En el ejercicio de la competencia comunicativa se distinguen los actos comunicativos y los actos del habla» ${ }^{2}$ Estos dos actos no se pueden producir en forma aislada porque «El acto del habla es un acto comunicativo que se realiza mediante el uso de una lengua oral o escrita ${ }^{3}$ En el proceso comunicativo un emisor codifica un mensaje con la intención de que otro sujeto (receptor) lo decodifique y lo comprenda. La competencia comunicativa también se nutre de otras subcompetencias. que hacen que la comunicación sea más explícita y completa.

La competencia Linguiística es una cualidad que posibilita a alguien crear un mensaje que puede ser comprendido mediante el uso correcto de la lengua. En este punto se tiene que llevar en cuenta la ortografía referida al uso apropiado de las letras, así como el uso adecuado de los signos de puntuación y signos auxiliares, entre otros. También la gramática que representa la competencia lingüística de los hablantes, especialmente en lo que se refiere a la morfología, la sintaxis y ciertos aspectos del léxico.

En algún momento dado de su vida, quién no habrá vacilado sobre cuál sería la forma más apropiada para decir una cosa. ¿Quién no se habrá hecho la pregunta? ¿Cómo le digo? ¿Será mejor hablar o escribir? Para resolver este tipo de dudas debemos desarrollar nuestra competencia discursiva que consiste en encontrar la manera más adecuada para manifestar una idea, teniendo en cuenta el contexto de la comunicación.

Cuando nos expresamos en forma oral o escrita es necesario crear textos coherentes y cohesivos de modo que el mensaje sea entendido. Esto lo vamos a lograr mediante la competencia textual. Con cada mensaje que se construye se tiene la intención de comunicar algo así como también se pretende lograr causar cierto efecto sobre el interlocutor, por ejemplo, el profesor que no construye adecuadamente su mensaje difícilmente pueda lograr ser entendido por los alumnos, por lo tanto, estaría poniendo en evidencia su falta de competencia pragmática.

Y llegamos a lo más específico, a lo que constituye un conjunto de saberes más particularizados, es decir, el mundo en el que un docente ya se encuentra más especializado. A éste se denomina competencia enciclopédica.

\footnotetext{
1 Maldonado, C. (1998) El uso del diccionario en el aula. Madrid: Editorial Arco libros.

2 Niño Rojas (2004). Semiótica y Lingüística aplicadas al español. Ediciones ECOE. Bogotá- Colombia, 2004.

3 Ob. Cit.
} 
Esperemos que hayamos desarrollado suficientemente nuestra competencia pragmática para convencernos de que todos los seres humanos necesitamos de la lengua para poder desarrollar nuestra competencia comunicativa y para que la misma sea eficaz necesitamos del enriquecimiento de vocabulario con el objeto de expresarnos mejor.

El diccionario no es un libro de lectura, es un libro de consulta, un complemento de otras herramientas que son necesarias para enriquecer nuestro léxico.

Una de ellas es la lectura que, según la primera acepción del Diccionario de la Real Academia Española, es: acción de leer que se complementa con la tercera acepción que dice: Interpretación del sentido de un texto, este último nos conduce hacia una lectura comprensiva que no solamente nos lleva a la mera acción de leer, sino que va más allá: se ajusta a la necesidad de comprender lo que se lee.

Según Marta Marín, tradicionalmente se ha dado mucha importancia al léxico en la comprensión lectora como si la mayor parte de la actividad de comprensión e interpretación residiera en saber el significado de las palabras. También menciona que la manera de solucionar las dificultades consistía siempre en la consulta del diccionario. Continúa diciendo que el vocabulario es apenas un aspecto. Además, afirma que según la mayoría de las teorías actuales de la lectura sostienen que un lector experto o en vía de serlo puede saltear las palabras desconocidas con la esperanza de inferir más adelante con la ayuda del mismo texto su significado, y eso da más fluidez a su lectura que si se detuviera en cada palabra a consultar un diccionario $^{4}$

Tradicionalmente se daba un enfoque muy tedioso al uso del diccionario, inclusive existen todavía en esta época algunos casos en que después de una lectura, generalmente en Lenguas, se le imponía al alumno que busque el significado de tales palabras, sin darles la oportunidad de examinar el significado de lo que realmente no comprende.

En ningún momento se puede concebir la idea de que la mayor parte de la actividad de comprensión e interpretación residiera en saber el significado de una palabra, volvemos a recordar en este espacio que el diccionario es un material de consulta que ayuda a comprender, no ha resolver completamente el problema. Cada lector debe ser capaz de entender el significado de una palabra dentro de un determinado contexto. Es así que podemos rescatar que el vocabulario es apenas un aspecto. Realmente, es así, es solo un aspecto, pero uno muy importante que puede disipar cualquier duda.

«Saltear las palabras desconocidas con la esperanza de inferir más adelante con la ayuda del mismo texto su significado» sería muy riesgoso porque quizás entre esas palabras salteadas pueda haber una que sea la clave para interpretar el texto. En lugar de saltear las palabras es recomendable que a medida que se realiza la lectura se las vaya subrayando, de modo que después de terminar la actividad de leer se pueda buscar en el diccionario el significado de las palabras. Recordemos que existen las lecturas superficiales y las lecturas profundas. Si la compresión de un texto nos lleva a realizar más de una lectura, pues hagámosla. Lo importante no es encontrar un lenguaje o estilo corriente y fácil, sino comprender lo que se lee porque para llegar a ser un lector experto es necesario "Contar con un vocabulario amplio, rico en expresiones» que «ayuda a escribir con mayor certeza.».

Existen diferentes tipos de diccionarios, entre los que se encuentra el normativo que nos indica información sobre una determinada palabra, así como la escritura correcta, la etimología, las diferentes acepciones simples y complejas. También están los de sinónimos y antónimos que nos ofrecen una lista de palabras que pueden tener significados parecidos o contrarios. A estos se suman los diccionarios bilingües, trilingües. Asimismo, se tienen los diccionarios especializados que recogen léxicos propios de una determinada rama del conocimiento.

\footnotetext{
${ }^{4}$ Marín, M. (1999). Lingüística y enseñanza de la lengua. Buenos Aires: Editorial AIQUE
} 
Considerando la clasificación de los diccionarios, es necesario conocer y hacer conocer el uso apropiado de cada uno de ellos porque muchas veces se cae en el error de afirmar que ciertas palabras ingresan al diccionario, sin tener en cuenta que puede ser, por ejemplo, vulgar o cuyo uso no es bien visto. En estos casos sería bueno conocer el tipo de diccionario que se consulta y el tipo de catálogo lexicográfico que recoge.

Además, es muy importante realizar las consultas en los diccionarios actualizados, es decir, aquellos que recogen las diferentes acepciones de las palabras porque lamentablemente se encuentran volúmenes muy simplificados donde no aparecen todas las acepciones, por lo que hace difícil que el consultante pueda tener un panorama completo de lo que significa una palabra, de ahí que no pueda lograrse la interpretación de un discurso.

Comprender el discurso, ya sea oral o escrito, conlleva muchos aspectos que parten desde la misma formulación. En la acepción diez de la entrada discurso del Diccionario de la Lengua Española encontramos: Lenguaje en acción, especialmente el articulado en unidades textuales. Esto nos indica que la lengua es una herramienta fundamental que mueve a los seres a expresarse, a exteriorizar lo que piensan, lo que sienten. En ese proceso de creación de unidades textuales influyen varios aspectos entre los que podemos resaltar el lingüístico. Cada palabra que se emplea tiene un significado contextual, así como sinónimos y antónimos.

Cabe señalar que muchas veces, no se ha logrado comprender el discurso debido a que se ha tenido una interpretación errónea del mismo, lo que, en muchas ocasiones, lo que en muchas ocasiones ha generado incluso algunos conflictos.

Con «el uso de los diccionarios como herramientas para el análisis del discurso» se pretende que estos ricos catálogos lexicográficos puedan mejorar la comprensión de los diferentes discursos, teniendo en cuenta que cada uno de ellos son el producto de años de trabajos que recogen las palabras; ya sea para indicar el uso normativo de las palabras, así como para señalar el uso contrastivo y diferencial, así también para indicar que se cuenta con una variedad léxica que se orienta a mejorar la expresión. Recordemos que a través de un discurso ya sea oral o escrito se tiene una intencionalidad comunicativa en donde la figura de los actores del proceso comunicativo se constituye en clave para lograr la comprensión del discurso porque un mensaje que no se codifica como corresponde difícilmente podrá interpretarse como corresponde para cerrar el circuito comunicativo.

La tecnología nos ofrece una infinidad de posibilidades de acceder a diccionarios digitales, por lo tanto, hoy en día no necesariamente tenemos que andar a cuestas con un diccionario impreso en papel. Si tenemos la intención de que el discurso sea comprendido, tenemos como compromiso contar con estas herramientas tan esenciales como son los diccionarios.

\section{REFERENCIAS}

Academia Paraguaya de la Lengua Española. Guaranismos en la lengua española. Asunción: Revista de la Academia Paraguaya de la Lengua Española. Vol. 1. Edición facsimilar 2010.

Aguiar, J. (2008) Diccionario del Castellano usual del Paraguay. Asunción. AGR Servicios Gráficos S.A.

Ahumada, I. (2007). Panorama de la Lexicografía regional del español. Costa Rica: Revista Artes y Letras, Universidad Costa Rics XXXI.

Baca de I. y Espínola B.E. Glosario de Paraguayismos en hijo de hombre de Augusto Roa Bastos, Asunción: CEADUC.

Ciro, L. (2009). Diccionarios e Internet: el caso del DEVA (Diccionario descriptivo del español del Valle de Aburrá).

Revista Virtual Universidad Católica del Norte. No.26 (febrero - mayo, Colombia). Recuperado de: http://revistavirtual.ucn.edu.co/index.php?option=com_content\&task=view\&id=58\&Itemid=

Propuesta de evaluación de diccionarios de uso, monolingües, semasiológicos y diferenciales sobre el español hablado en Antioquia. Medellín: La Carrera Editores Investigaciones Lingüísticas en Antioquia.

Maldonado, C. El uso del diccionario en el aula. Madrid: Editorial Arco libros. 1998

Marín, M. (1999) Lingüística y enseñanza de la lengua. Buenos Aires: Editorial AIQUE.

Porto Dapena, J. (2002). Manual de técnica lexicográfica. Madrid: Arco libros. 
Niño Rojas. (2004) Semiótica y Lingüística aplicados al español. Bogotá-Colombia.

Real Academia de la Lengua Española. Diccionario de la Lengua Española. 2014

Salvador, G. (1985). Semántica y Lexicología del Español. Estudios y lecciones. Madrid: Paraninfo.

Seco, M. (2003). Estudios de Lexicografía Española. Madrid:Gredos.

Gramática esencial de la lengua española. (1999). Madrid: Espasa Calpe.

Vera H., Scavone, A. El verdadero diccionario paraguayo (las palabras no son los que parecen). Servilibro: Asunción. https://www.wordreference.com/sinonimos/diccionario 